\title{
Aspirin Prolongs Bleeding Time in Uremia by a Mechanism Distinct from Platelet Cyclooxygenase Inhibition
}

Flavio Gaspari, Gianluigi Vịanò, Silvia Orisio, Maurizio Bonati, Manuela Livio, and Giuseppe Remuzzi Mario Negri Institute for Pharmacological Research, 24100 Bergamo and 20157 Milan; and Division of Nephrology and Dialysis, Ospedali Riuniti di Bergamo, 24100 Bergamo, Italy

\begin{abstract}
We reported that aspirin (ASA) abnormally prolongs bleeding time (BT) in uremia. The present study was designed to investigate whether (a) the abnormally prolonged post-ASA BT in uremia is due to different ASA pharmacokinetics and bioavailability that might be a consequence of uremic condition, (b) platelet cyclooxygenase is peculiarly sensitive to ASA in uremia, and (c) ASA affects primary hemostasis in uremia by a mechanism independent of cyclooxygenase inhibition. Our results showed that in patients with uremia, but not in normal subjects, ASA markedly prolongs the BT. This effect is transient and depends on the presence of ASA in the blood. The observed differences in ASA kinetic parameters are not an explanation of the exaggerated effect of ASA on primary hemostașis in uremia. The sensitivity of platelet cyclooxygenase to ASA inhibition is comparable in uremics and in normal subjects. The temporal dissociation between ASA-induced prolongation of BT and the effect on platelet thromboxane $A_{2}$ generation suggests that ASA inhibits platelet function in uremia by a mechanism distinct from cyclooxygenase blocking. This possibility is strengthened by the observation that ibuprofen at a dose that fully inhibits platelet cyclooxygenase activity does not significantly prolong BT.
\end{abstract}

\section{Introduction}

Aspirin (ASA) ${ }^{1}$ has been used in uremic patients on chronic hemodialysis to prevent thrombosis of the arterovenous shunt (1). The rationale for the dose and schedule of administration employed was to inhibit platelet thromboxane $A_{2}\left(T x A_{2}\right)$ generation without affecting vascular prostacyclin $\left(\mathrm{PGI}_{2}\right)(2)$. Paradoxically, besides being exposed to thrombotic complications, uremic patients also have a bleeding tendency thought to be due to platelet functional abnormalities (3-6).

A recent study (7) analyzed the effect of ASA on primary hemostasis in uremia, measuring cutaneous bleeding time (BT) as an overall marker of platelet function. It was found that the same dose of ASA prolonged BT more in uremic than in control

Dr. Livio is a Researcher of the National Research Council (CNR) Center of Cytopharmacology, University of Milan.

Address reprint requests to Dr. Remuzzi, Mario Negri Institute for Pharmacological Research, Via Gavazzeni, 11, 24100 Bergamo, Italy.

Received for publication 14 August 1986 and in revised form $10 \mathrm{Feb}$ ruary 1987

1. Abbreviations used in this paper: ASA, aspirin; BT, bleeding time; $\mathrm{PGI}_{2}$, prostacyclin; $\mathrm{SA}$, salicylic acid; $\mathrm{Tx}$, thromboxane.

J. Clin. Invest.

(c) The American Society for Clinical Investigation, Inc.

$0021-9738 / 87 / 06 / 1788 / 10 \quad \$ 1.00$

Volume 79, June 1987, 1788-1797 subjects, suggesting uremic platelets were more susceptible to the inhibitory effect of ASA. This might be due to different ASA pharmacokinetics and bioavailability that might be influenced by the uremic condition (8). Alternatively, assuming that the platelet-inhibitory activity of ASA is related to the fact that it irreversibly acetylates platelet cylooxygenase $(9,10)$ and considering that platelet cyclooxygenase may be abnormal in uremia (11), the greater prolongation of BT might derive from a peculiar sensitivity of uremic platelet cyclooxygenase to ASA. Finally, ASA might affect primary hemostasis in uremia by a mechanism independent of cyclooxygenase inhibition.

We have analyzed the issue of abnormal prolongation of BT by ASA in uremia. Because no data are yet available on ASA pharmacokinetics in uremics, we adapted a method described previously and investigated the relationship between ASA-induced prolongation of BT and ASA kinetic parameters. The relationship between ASA-induced prolongation of BT and its inhibitory activity on platelet $\mathrm{TxA}_{2}$ generation was also investigated.

The present results add some further elements to the complex issue of uremic bleeding tendency and the effect of ASA on primary hemostasis in these patients.

\section{Methods}

Subjects. Three groups of subjects participated in this study: (a) 18 patients (10 men and 8 women with a median age of $46 \mathrm{yr}$, range 24-69) with chronic renal failure with anuria. These patients were on regular hemodialysis $\left(12 \mathrm{~h} / \mathrm{m}^{2}\right.$, three sessions per week, parallel flow kidney with cuprophan membrane) and were selected on the basis of a hematocrit value $>30 \%$ (up to $48 \%$; mean \pm SD $37 \pm 4 \%$ ) and a normal or slightly prolonged BT (mean \pm SD $7.88 \pm 0.64 \mathrm{~min}$ ). They were studied $24 \mathrm{~h}$ after the end of the first dialysis session. (b) 12 patients (seven men and five women with a median age of $45 \mathrm{yr}$, range 23-71) with different degrees of renal impairment. These patients had not yet been included in a dialysis program. (c) 11 healthy volunteers, members of the Institute staff (six men and five women with a median age of $27 \mathrm{yr}$, range 24-31) with no renal disease (creatinine clearance $>60 \mathrm{ml} / \mathrm{min}$ per $1.73 \mathrm{~m}^{2}$ body surface area.

No patient or control had taken drugs that affect platelet behavior for at least $20 \mathrm{~d}$ before the start of the study. All the subjects gave informed consent according to the Declaration of Helsinki.

Study design. Starting from the report of Harter et al. (1), who found in a randomized double-blind trial that an oral dose of $160 \mathrm{mg}$ of ASA prevented shunt thrombosis in patients on hemodialysis, we studied the effect of a $160-\mathrm{mg}$ oral ASA regimen on BT in relation to ASA bioavailability and to platelet $T \times A_{2}$ generation.

In patients on chronic hemodialysis with anuria, the body weight varies in the interdialytic period according to fluid intake. To minimize this variable and the possible influence of unpredictable absorption on ASA bioavailability, we also gave uremics and controls $100 \mathrm{mg} / \mathrm{m}^{2}$ ASA by intravenous injection and evaluated its effect on platelet function as before.

The pharmacokinetic studies were performed in five patients and five controls with both administration routes. All the subjects fasted for 
at least $12 \mathrm{~h}$ before the study and they received on two separate occasions, with a 15-d washout interval, a 160-mg oral dose of ASA (as capsules prepared by directly weighing ASA) swallowed with $100 \mathrm{ml}$ of water and a $100-\mathrm{mg} / \mathrm{m}^{2}$ intravenous dose (Quinton, Neopharmed, Bollate, Italy). Blood samples were collected from an antecubital vein through a 19gauge needle and were rapidly transferred into precooled vials containing $50 \mu \mathrm{l}$ of $50 \%$ potassium fluoride and $50 \mu \mathrm{l}$ of a heparin solution $(1,000$ $\mathrm{IU} / \mathrm{ml})$. After immediate centrifugation at $4^{\circ} \mathrm{C}(2,000 \mathrm{~g}$ for $20 \mathrm{~min})$, plasma was separated and immediately stored at $-80^{\circ} \mathrm{C}$ for analysis within $2 \mathrm{wk}$. The loss of ASA through this procedure was $<5 \%$. Venous blood was drawn immediately before and $2,5,10,15,20,25,30,40$, $50,60,75,90,120,150,180 \mathrm{~min}$, and $16 \mathrm{~h}$ after each ASA dose for the pharmacokinetic study. During the first $3 \mathrm{~h}$ after ASA, blood was drawn through the butterfly needle left in the vein. The line was kept open by slowly dripping sterile saline.

To obtain additional information on the relationship between ASAinduced prolongation of BT and platelet cyclooxygenase inhibition, ASA $(160 \mathrm{mg})$ was administered twice in three uremic patients on chronic hemodialysis, and $\mathrm{BT}$ and serum $\mathrm{TxB}_{2}$ were studied immediately before each dose of ASA and $30 \mathrm{~min}, 1,2$, and $16 \mathrm{~h}$ after administration. These patients received the second oral dose of ASA when the effect of the first dose had worn off but serum $T_{x B}$ was still inhibited.

To obtain information on the effect of another cyclooxygenase inhibitory substance, three uremic patients on chronic hemodialysis and three controls received an oral dose ( $400 \mathrm{mg}$ ) of ibuprofen (Brufen, Formenti s.p.a., Milan, Italy), which has been found to suppress platelet cyclooxygenase activity by $>90 \%$.

To investigate whether ASA-induced prolongation of BT was related to the degree of renal impairment, we studied the effect of a $160-\mathrm{mg}$ oral dose of ASA on BT and serum $\mathrm{TxB}_{2}$ in three normal subjects and 12 patients with different degrees of renal impairment before they needed dialysis treatment. Details on the degree of renal impairment are given in Table I.

Bleeding time. Template BT was measured with the Simplate II device (General Diagnostic, Milan) on the antecubital surface of the forearm, under a counter pressure of $50 \mathrm{mmHg}$. The blood was blotted every 30 $s$ until no more appeared at the site of transverse standard incisions. Results were expressed as the average BT from two horizontal incisions. The normal range with this method in 15 healthy women and 15 healthy men was 3-7 min. The time schedule of BT measurements was based on the results of a pilot pharmacokinetic study in three patients. The following times were chosen for BT measurements: $(a)$ before ASA; $(b)$ $1 \mathrm{~h}$ after ASA, when the absorption phase was completed in all subjects and maximal plasma concentrations were already reached; $(c) 2 \mathrm{~h}$ after ASA, when plasma levels were $<10 \%$ of peak concentrations; (d) $16 \mathrm{~h}$ after ASA, when the drug was no longer detectable in plasma.

In the group of patients who received two doses of ASA as well as in the group of subjects with different degrees of renal impairment, BT was measured with the same time schedule described above. In addition, in these partícular study groups we have also added a measurement of BT at 30 min to obtain an earlier time point coinciding with the peak plasma ASA concentration. In the ibuprofen-treated subjects BT was measured before and 1,2 , and $16 \mathrm{~h}$ after drug administration.

Pharmacokinetic assays. Plasma concentrations of ASA and salicylic acid (SA) in healthy volunteers have been determined by high-performance liquid chromatography (HPLC) as described in details by Mays et al. (12). The above mentioned method cannot be used in renal failure patients because organic waste compounds which accumulate in uremia can interfere with the assay and amounts of ASA $<1 \mu \mathrm{g} / \mathrm{ml}$ cannot be measured. Thus for studying uremic patients it was necessary to resort to the HPLC that we describe in this section and have reported in detail elsewhere (13). Briefly: $200 \mu$ l of plasma was added to a centrifuge tube containing $15 \mu \mathrm{l}$ of $7 \mathrm{M} \mathrm{H}_{3} \mathrm{PO}_{4}, 80 \mathrm{mg} \mathrm{NaCl}, 40 \mu \mathrm{l}$ of $\mathrm{H}_{2} \mathrm{O} / \mathrm{CH}_{3} \mathrm{OH}$ 1: 1 , and $50 \mu \mathrm{l}$ of $p$-toluic acid $(20 \mu \mathrm{g} / \mathrm{ml})$ as internal standard. To each tube $8 \mathrm{ml}$ of hexane was added, and the samples were shaken for 15 min. After centrifugation, the organic layer was separated and evaporated to dryness. The residue was dissolved in $200 \mu \mathrm{l}$ of mobile phase and 100 $\mu \mathrm{l}$ was injected into the liquid chromatograph. Using a model 342 liquid chromatograph equipped with a model $160 \mathrm{UV}$ detector (Beckman Instruments, Inc., Fullerton, CA) operating at $229 \mathrm{~nm}$ and a reversed-

Table I. Bleeding Time* before and after $160 \mathrm{mg}$ of ASA in Four Groups of Three Patients with Various Degrees of Renal Impairment Who Were Not Subjected to Dialysis and in Three Normal Subjects Studied Simultaneously as a Control Group

\begin{tabular}{|c|c|c|c|c|c|c|c|c|}
\hline \multirow[b]{2}{*}{ Groups } & \multirow[b]{2}{*}{ Subjects } & \multirow[b]{2}{*}{ Body weight } & \multirow[b]{2}{*}{$\begin{array}{l}\text { Serum } \\
\text { creatinine }\end{array}$} & \multicolumn{5}{|c|}{ Bleeding time } \\
\hline & & & & Basal & $30 \mathrm{~min}$ & $1 \mathrm{~h}$ & $2 \mathrm{~h}$ & $16 \mathrm{~h}$ \\
\hline & & $k g$ & $m g / d l$ & $\min$ & $\min$ & $\min$ & $\min$ & $\min$ \\
\hline \multirow[t]{3}{*}{ Moderate } & A.T. & 58 & 2.9 & 6 & 7 & 7.5 & 7 & 6.5 \\
\hline & B.R. & 61 & 2.8 & 5.5 & 6 & 6.5 & 6 & 6 \\
\hline & F.B. & 53 & 3 & 6 & 6 & 7 & 7 & 7 \\
\hline \multirow[t]{3}{*}{ Mild } & P.S. & 51 & 5 & 7.5 & 9 & 11 & 9 & 8 \\
\hline & A.L. & 52 & 6 & 7 & 8 & 9 & 8 & 8 \\
\hline & M.L. & 57 & 5 & 6 & 7.5 & 12 & 8 & 6.5 \\
\hline \multirow[t]{3}{*}{ Severe } & B.L. & 60 & 7.5 & 8 & 9.5 & 17 & 11 & 8 \\
\hline & D.A. & 57 & 6.5 & 8 & 10 & 16 & 10 & 7.5 \\
\hline & R.B. & 56 & 8 & 7.5 & 10 & 14 & 9.5 & 8 \\
\hline \multirow[t]{3}{*}{ Severe } & T.T. & 61 & 10 & 7 & 10.5 & 13 & 10 & 8.5 \\
\hline & B.A. & 60 & 11 & 8 & 11 & 17 & 11 & 8.5 \\
\hline & R.A. & 54 & 10 & 6 & 10.5 & 18 & 10 & 8 \\
\hline \multirow[t]{3}{*}{ Control } & A.S. & 58 & 0.8 & 4 & 5 & 5.5 & 4 & 4 \\
\hline & R.S. & 62 & 0.9 & 5.5 & 6 & 6.5 & 6 & 5 \\
\hline & G.C. & 60 & 1 & 4 & 5 & 5 & 4 & 4 \\
\hline
\end{tabular}

Serum $\mathrm{TxB}_{2}$ percent inhibition was $0 \%$ before aspirin administration and $>90 \%$ after drug administration. ${ }^{*}$ Bleeding time: normal values $3-7$ $\min$. 
phase column (LiChrosorb RP-8, $7 \mu \mathrm{m}, 250 \mathrm{~mm} \times 4 \mathrm{~mm}$, E. Merck, Darmstadt, Federal Republic of Germany), the samples were eluted in isocratic conditions with a mobile phase of $30 \%(\mathrm{vol} / \mathrm{vol})$ acetonitrile in water at $\mathrm{pH} 2.5 \pm 0.2$ with $\mathrm{H}_{3} \mathrm{PO}_{4}$ at a $1.0-\mathrm{ml} / \mathrm{min}$ flow rate. The retention times of ASA, SA, and p-toluic acid were 5.9, 8.0, and $9.6 \mathrm{~min}$, respectively. Internal calibration curves of ASA and SA were prepared for each set of samples. Linearity was found over the investigated concentration range. The detection limit was $0.1 \mu \mathrm{g} / \mathrm{ml}$ for both compounds. Pharmacokinetic parameters for ASA and SA were calculated by the noncompartmental pharmacokinetic method according to Gibaldi and Perrier (14). Before starting the experiments, the equivalence of the two methods used was validated as follows. In vitro, identical ASA concentrations were detected (see Results), comparing Mays's and our own method in uremic and control plasma added with known amounts of ASA. In vivo, both methods were applied to ASA pharmacokinetic parameters after $160 \mathrm{mg}$ of ASA per os obtaining perfectly superimposed curves of plasma concentration-time profiles (data not shown).

Protein binding. Protein binding of ASA and SA was measured by ultrafiltration using the Centricon 10 Microconcentrator system (Amicon Corp., Danvers, MA), placing in the sample reservoir 2-ml portions of plasma obtained from uremic patients or healthy volunteers after the intravenous dose $\left(100 \mathrm{mg} / \mathrm{m}^{2}\right)$ of ASA. The plasma was collected at $37^{\circ} \mathrm{C}$ on heparin and centrifuged at $3,000 \mathrm{~g}$ for 15 min using a Beckman model J2-21 centrifuge (Beckman Instruments, Inc.) with a fixed-angle rotor (JA-21, angle $\left.40^{\circ}\right)$. The collected volume of ultrafiltrate ranged between $10 \%$ and $15 \%$ of the initial sample volume. The percentage of binding was determined as follows: percent bound: $(T-F) / T \times 100$, where $F$ denotes the free drug concentration determined in the ultrafiltrate and $T$ is the total drug concentration introduced into the system. The concentrations were determined by the HPLC techniques described above.

Serum $T x B_{2}$. Samples for studying platelet $\mathrm{TxB}_{2}$ production in response to endogenous thrombin were obtained by taking 3-ml native blood samples from the same venipuncture as for the pharmacokinetic study to assay serum $\mathrm{TxB}_{2}$ levels. The samples were incubated at $37^{\circ} \mathrm{C}$ for $60 \mathrm{~min}$, and centrifuged at $2,000 \mathrm{~g}$ for $10 \mathrm{~min}$. The serum was frozen and stored for analysis. $\mathrm{TxB}_{2}$, the stable breakdown product of $\mathrm{TxA}_{2}$, was assayed in unextracted serum preparations (11). Serum was assayed at a final dilution of 1:150 to 1:15,000. 5,000 dpm of $\left[{ }^{3} \mathrm{H}\right] \mathrm{T} \times \mathrm{B}_{2}$, and sufficient specific rabbit antibodies to bind $40 \%$ of the tritiated compound were incubated $16-24 \mathrm{~h}$ at $4^{\circ} \mathrm{C}$ in a final volume of $1.5 \mathrm{ml}$ in each assay tube. Anti-TxB $\mathrm{B}_{2}$ was used at a final dilution of 1:250,000. Free and antibody-bound tritiated compound were separated by rapid addition of 5 $\mathrm{mg}$ of uncoated charcoal (Norit A), which adsorbs $95-98 \%$ of free Tx. Immediately before the addition of charcoal, $0.1 \mathrm{ml}$ of human $\mathrm{Tx}$ was added to each tube to prevent the adsorption of antibody-bound Tx. 0.1 $\mathrm{ml}$ of charcoal suspension in $0.02 \mathrm{M}$ phosphate buffer, $\mathrm{pH} 7.4(50 \mathrm{mg} /$ $\mathrm{ml}$ ), was then added to each sample, which was shaken by a Vortex mixer (Cenco Laboratories, Milan) and centrifuged for $20 \mathrm{~min}$ at 2,000 $g$ at $4{ }^{\circ} \mathrm{C}$. The supernatant solution containing antibody-bound $\mathrm{TxB}_{2}$ was decanted directly into $10 \mathrm{ml}$ of Instagel II (Packard Instrument Co. Inc., Downers Grove, IL). Radioactivity of samples was counted in a liquid scintillation counter (model LS 1800, Beckman Instruments, Inc., Irvine, CA). The smallest concentration that could be measured with $95 \%$ confidence was $2 \mathrm{pg} / \mathrm{ml}$ for the antiserum, consequently the detection limit for serum $\mathrm{TxB}_{2}$ was $15 \mathrm{pg} / \mathrm{ml}$. Results were expressed as nanograms per milliliter of $\mathrm{TxB}_{2}$.

Statistical analysis. The values for BT were not normally distributed, and differences were compared by Friedman's test (15). The remaining data were analyzed by Student's $t$ test and analysis of variance (16). Results are expressed as means \pm standard deviations. $P$ values $<0.05$ were considered significant.

\section{Results}

Bleeding time. Cutaneous BT is an overall test of platelet function, and compelling evidence now suggests that $\mathrm{BT}$ is the best marker of clinical bleeding in uremia $(6,17,18)$. To assess the mechanism(s) by which ASA inhibits platelet function in uremia, we measured BT in relation to different plasma ASA concentrations in uremic patients and normal subjects. Fig. 1 shows that in uremics the pre-ASA BT values were normal or slightly prolonged. $1 \mathrm{~h}$ after ASA, the values were $>15 \mathrm{~min}$ in all 12 patients $(P<0.01)$. The prolongation of BT in uremics was independent of the route of administration in that both oral and intravenous ASA induced a comparable increase in BT. In normal subjects, BT $1 \mathrm{~h}$ after oral or intravenous ASA was not significantly prolonged $(6.20 \pm 0.53$ and $5.90 \pm 0.38 \mathrm{~min}$, respectively) in comparison with basal values $(5.70 \pm 0.31 \mathrm{~min})$. In both uremic patients and normal subjects, BT was also measured 2 and $16 \mathrm{~h}$ after oral or intravenous ASA. BT $2 \mathrm{~h}$ after ASA showed a tendency to be longer than the basal value $(10.08 \pm 0.71 \mathrm{~min}$ per os and $9.88 \pm 0.64 \mathrm{~min}$ intravenous, $P<0.01)$ in uremics, but not in controls $(5.92 \pm 0.67 \mathrm{~min}$ per os and $5.81 \pm 0.40 \mathrm{~min}$ intravenous). $16 \mathrm{~h}$ after ASA, BT was not significantly different from the basal value both in uremics $(8.13 \pm 0.64 \mathrm{~min}$ per os and $8.19 \pm 0.50 \mathrm{~min}$ intravenous) and in control subjects $(5.70 \pm 0.30$ min per os and $5.60 \pm 0.21$ min intravenous). Thus, in this study oral and intravenous moderate doses of ASA markedly prolonged BT in uremics but not in control subjects.

Table II shows the results obtained when ASA was given twice to uremic patients. This study was done to evaluate the effect of a second dose of ASA administered when the effect of the first one had worn off but the serum Tx was still $>90 \%$ suppressed. No significant differences were found in term of post-ASA BT between the first and the second ASA administration. Ibuprofen, used as an alternative to ASA as the cyclooxygenase inhibitor, did not modify the BT values at the different intervals considered (Fig. 2).

Fig. 3 shows highly significant correlation $(r=0.920, P$ $<0.0001$ ) between post-ASA BT prolongation and serum creatinine, indicating that the abnormal prolongation of post-ASA BT is related to the degree of renal impairment.

Pharmacokinetics. The pilot experiment showed that the two methods used for pharmacokinetic analysis were comparable (Table III). Because drug pharmacokinetics may be influenced by uremia (8), and to determine whether the abnormal prolongation of BT induced by ASA in uremic patients was due to different ASA pharmacokinetics or bioavailability, we analyzed the plasma concentration-time profiles of ASA and its major metabolite, SA, in uremic patients and controls.

ASA absorption after oral dosing was rapid (Fig. 4): the drug was detected in plasma within $5 \mathrm{~min}$ and the mean peak plasma concentrations were $2.79 \pm 0.72 \mu \mathrm{g} / \mathrm{ml}$ in patients and $3.45 \pm 1.78$ $\mu \mathrm{g} / \mathrm{ml}$ in controls at $23.2 \pm 4.3$ and $32.0 \pm 13.5 \mathrm{~min}$, respectively. The elimination half-life $\left(t_{1 / 2}\right)$ was short and similar in both patients and controls (21.5 \pm 5.2 and $19.7 \pm 5.7 \mathrm{~min}$, respectively). Table IV shows that apparent volume of distribution $(V)$ and total body clearance (CL) were higher in uremics than in controls but only for CL the difference reached a statistically significant value $(P<0.02)$. The area under the plasma concentrationtime curve (AUC) was lower in uremics than in controls $(P$ $<0.01)$. Table IV shows that after intravenous ASA $t_{4 / 2}$ was similar in both patients and controls (14.4 \pm 4.4 and $17.3 \pm 1.4 \mathrm{~min}$, respectively) and shorter than after oral dose. As for oral dose, $\mathrm{V}$ and $C L$ after intravenous administration of ASA were higher in uremics than in controls but only for CL the difference reached a statistically significant value. AUC was significantly lower in uremics than in controls $(P<0.01)$. After the oral dose of ASA, 
UREMICS
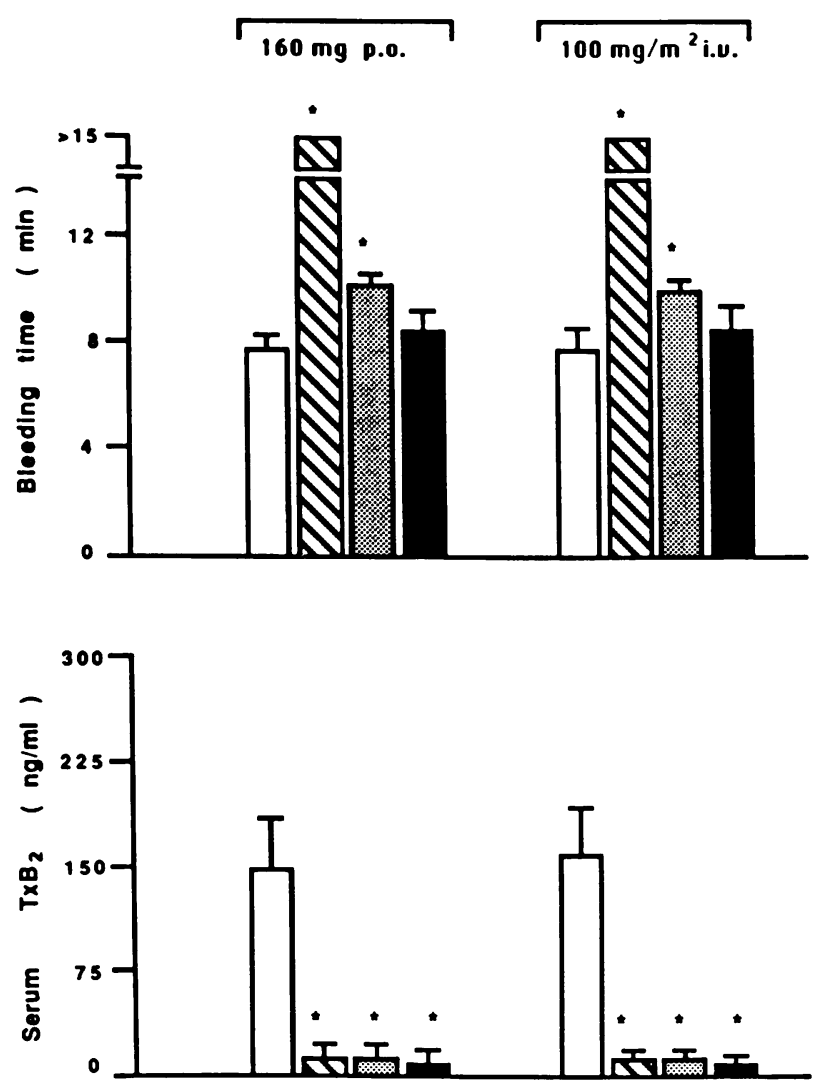

CONTROLS
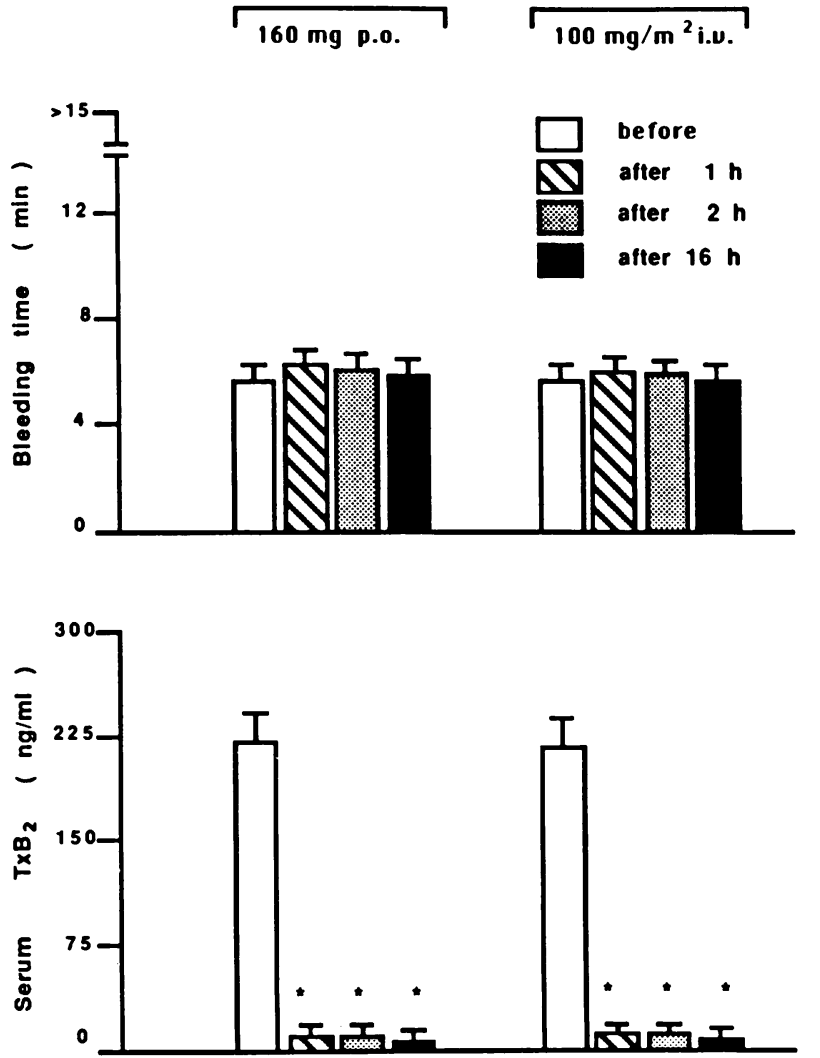

Figure 1. Bleeding time measurements and serum $\mathrm{TxB}_{2}$ levels before and after ASA administration in uremic patients and normal subjects. ${ }^{*} P<$ 0.01 vs. basal values.

SA levels rose rapidly and eventually exceeded those of ASA in both uremics and controls. Maximum concentration was reached at $1.44 \pm 0.62 \mathrm{~h}$ in uremics and $1.04 \pm 0.34 \mathrm{~h}$ in controls, the peak concentrations being lower in patients than in controls $(P<0.02)$ (Table V). SA $t_{1 / 2}$ was $3.27 \pm 1.76 \mathrm{~h}$ in uremics and $2.48 \pm 0.35 \mathrm{~h}$ in controls; this difference was not statistically significant. After intravenous ASA, peak SA concentrations in plasma were reached after $0.86 \pm 0.38$ and $0.55 \pm 0.16 \mathrm{~h}$, respectively, in uremics and controls. The mean peak concentration was lower in patients than in controls (Table V), but the difference was not statistically significant. The $t_{1 / 2}$ was $2.37 \pm 1.27 \mathrm{~h}$ in uremics and $2.38 \pm 0.60 \mathrm{~h}$ in controls. AUC were not significantly different but lower in uremics than in controls (Table V).
The differences in ASA V, CL, and AUC as well as in SA AUC between uremic patients and controls can be explained by the differences in protein binding for ASA and SA. One of the consequences of renal failure is a decrease in the ability of plasma protein to bind certain drugs. As a consequence the apparent drug volume distribution may increase (8). We compared ASA and SA protein binding in uremics as compared with control subjects. Plasma protein binding of ASA and SA was lower in uremics $(33.1 \pm 5.6 \%$ for ASA and $91.2 \pm 1.5 \%$ for SA) than in control subjects $(64.4 \pm 2.4 \%$ for ASA and $95.1 \pm 1.3 \%$ for SA) (Table VI). To assess whether the differences in the two groups were due to a reduced protein concentration or to an abnormality of the binding, we measured the concentrations of plasma total

Table II. Bleeding Time* Measurements after Two Administrations of ASA in Two Consecutive Days

\begin{tabular}{|c|c|c|c|c|c|c|c|c|c|c|}
\hline \multirow[b]{2}{*}{ Patients } & \multicolumn{5}{|c|}{$160 \mathrm{mg}$ (first dose of aspirin) } & \multicolumn{5}{|c|}{$160 \mathrm{mg}$ (second dose of aspirin) } \\
\hline & Basal & $30 \mathrm{~min}$ & $1 \mathrm{~h}$ & $2 \mathrm{~h}$ & $16 \mathrm{~h}$ & Basal & $30 \mathrm{~min}$ & $1 \mathrm{~h}$ & $2 \mathrm{~h}$ & $16 \mathrm{~h}$ \\
\hline & $\min$ & $\min$ & $\min$ & $\min$ & $\min$ & $\min$ & $\min$ & $\min$ & $\min$ & $\min$ \\
\hline A.C. & 7 & 10 & 16 & . 11 & 7.5 & 7.5 & 9 & 17 & 11 & 8 \\
\hline D.Q. & 7.5 & 10 & 14 & 10.5 & 8.5 & 8 & 10 & 13 & 10.5 & 8.5 \\
\hline C.A. & 6 & 9 & 18 & 11 & 7 & 7 & 9.5 & 15 & 10 & 8 \\
\hline
\end{tabular}

Serum $\mathrm{TxB}_{2}$ percent inhibition was $0 \%$ before the first aspirin administration and $>90 \%$ at any time after aspirin administration. $*$ Bleeding times: normal values 3-7 min. 

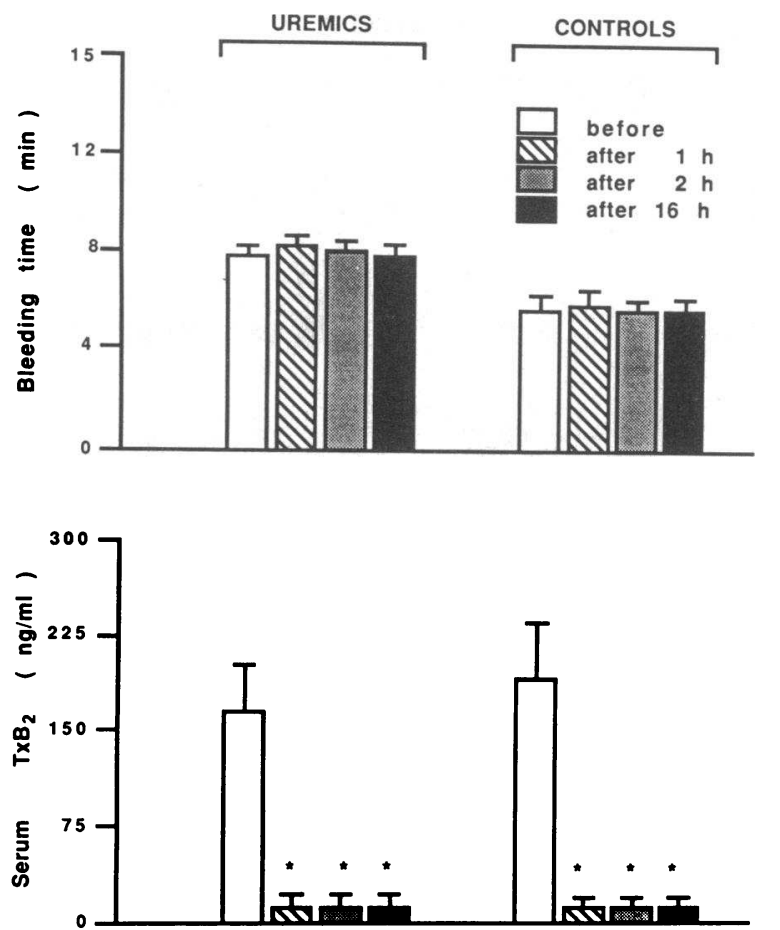

Figure 2. Bleeding time measurements and serum $\mathrm{TxB}_{2}$ levels before and after ibuprofen administration in uremic patients and normal subjects. ${ }^{*} P<0.01$ vs. basal values.

protein and albumin in uremics and controls. No significant differences were found for either parameter between uremics and controls (footnote to Table VI), indicating that the abnormal ASA protein binding in uremics must depend either on a competitive displacement by uremic toxins or on an abnormality in the structural arrangement of albumin $(19,20)$.

When plasma protein binding decreases the kinetic parameters for unbound drug may change. We calculated peak concentrations, CL, V, and AUC of unbound ASA in uremics and controls. A significantly lower unbound V $(P<0.02$; data not

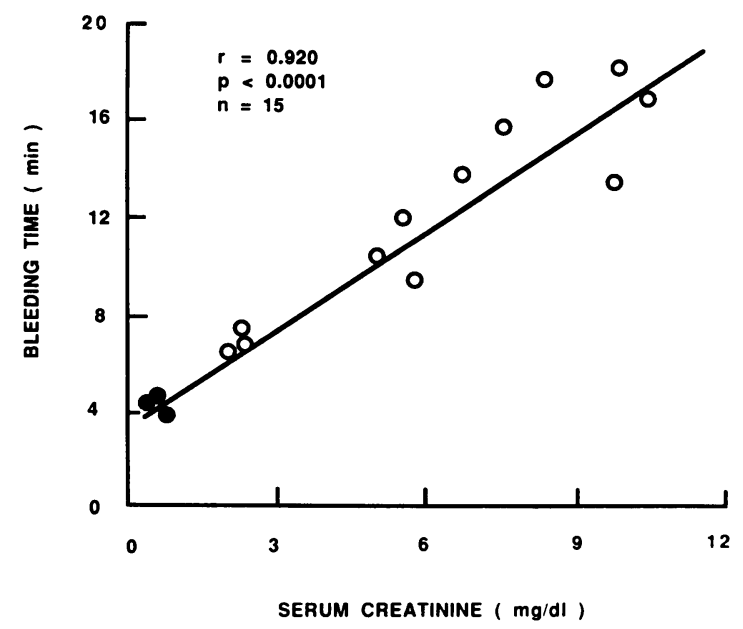

Figure 3. Relationship between post-ASA bleeding time $(1 \mathrm{~h})$ and serum creatinine levels in patients with various degrees of renal impairment and normal subjects.
Table III. Pilot Study of Comparison between the Two HPLC Methods Used to Study ASA Pharmacokinetic Parameters

\begin{tabular}{llll}
\hline Plasma & $\begin{array}{l}\text { Added ASA } \\
\text { concentration }\end{array}$ & \multicolumn{1}{l}{$\mathrm{A}^{*}$} & \multicolumn{1}{l}{$\mathrm{B}^{*}$} \\
\hline \multirow{4}{*}{ Uremic } & $\mu \mathrm{g} / \mathrm{ml}$ & $\mu \mathrm{g} / \mathrm{ml}$ & $\mu \mathrm{g} / \mathrm{ml}$ \\
& 10.00 & $10.07 \pm 0.44$ & $10.12 \pm 0.52$ \\
& 2.00 & $2.06 \pm 0.10$ & $2.03 \pm 0.18$ \\
& 0.20 & $0.19 \pm 0.02$ & Not measurable \\
Control & 10.00 & $10.26 \pm 0.20$ & $9.98 \pm 0.34$ \\
& 2.00 & $1.98 \pm 0.06$ & $2.04 \pm 0.08$ \\
& 0.20 & $0.21 \pm 0.02$ & $0.20 \pm 0.04$ \\
\hline
\end{tabular}

* Present method (13)

${ }^{\ddagger}$ Method of Mays et al. (12)

shown) in uremic patients after intravenous administration of ASA than in controls was found. Other kinetic parameters for unbound ASA were not significantly different between the two groups.

To evaluate whether the observed differences in concentration of unbound drug were responsible for the exaggerated prolongation of post-ASA BT in uremics in comparison with controls, we administered to three additional normal subjects a higher dose of intravenous ASA in order to reach values of unbound drug comparable to those found in uremics. We found that in this additional group of normal subjects receiving 160 $\mathrm{mg} / \mathrm{m}^{2}$ intravenous ASA, plasma concentrations of unbound drug were comparable $(0.22 \pm 0.08 \mu \mathrm{g} / \mathrm{ml})$ to those of uremics given $100 \mathrm{mg} / \mathrm{m}^{2}$ intravenous ASA $(0.24 \pm 0.12 \mu \mathrm{g} / \mathrm{ml})$. However, such concentrations of unbound drug did not prolong BT $1 \mathrm{~h}$ after ASA in normals $(5.30 \pm 0.25 \mathrm{~min})$, thus indicating that differences in the level of unbound drug cannot explain the differences in post-ASA BT between uremics and controls.

In addition, the bioavailability of ASA was not significantly different in uremics and controls. Table IV shows $54.4 \%$ ASA bioavailability in uremics versus $58.1 \%$ in normal subjects. This latter value is in agreement with the results reported by Pedersen and FitzGerald (21). Because AUC is a measure of the dose reaching the sampling site, this indicates that $45.6 \%$ and $41.9 \%$, respectively, of the administered oral ASA does not reach the peripheral circulation.

A possible explanation for these findings is that ASA given orally may not be completely absorbed, but this cannot be the case in the light of our data (Table V) showing that the AUC of ASA metabolite (in relation to the dose) was not significantly different after oral or intravenous ASA for either uremic patients or controls. Thus it appears that ASA is completely absorbed in uremics, as reported for controls (22), and hydrolysis by intestinal and plasma esterases must account for its peculiar bioavailability.

Taken altogether, the present results indicate that the abnormal effect of ASA on primary hemostasis in uremia is likely to be independent of the drug pharmacokinetics or bioavailability but depends on the presence of ASA in plasma inasmuch as the effect on BT can no longer be demonstrated when plasma ASA concentrations are undetectable. Nonetheless, it has to be pointed out that the relationship between plasma ASA and BT is not a single one: for instance, in the subjects who were given two doses of oral ASA and had BT determinations at $30 \mathrm{~min}$ and $1 \mathrm{~h}$, maximum BT prolongation followed peak plasma ASA by a 

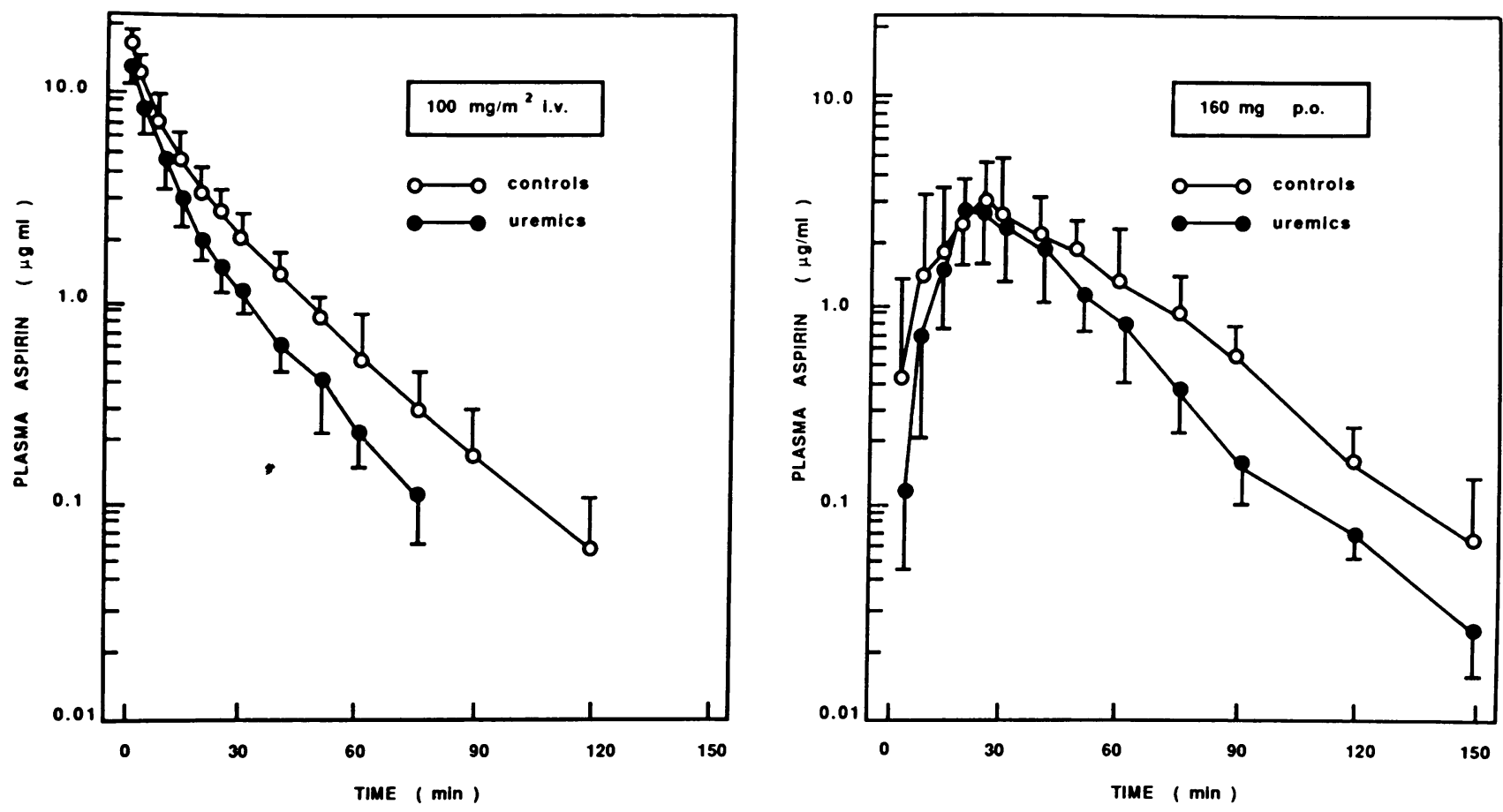

Figure 4. Plasma concentrations of ASA in uremic patients and normal subjects after intravenous and oral administration.

considerable time. The explanation for this phenomenon is not obvious on the basis of the data presented here.

Serum $T x B_{2}$. Acetylation of platelet cyclooxygenase by oral ASA has been shown to be dose-dependent and cumulative with repeated administration (23). To assess the relationship between the effect of ASA on BT and its capacity to inhibit platelet cyclooxygenase, we studied the time course of serum $\mathrm{TxB}_{2}$ formation at different intervals after ASA doses in uremics and normal subjects. During whole blood clotting in vitro, endogenous thrombin activates platelet arachidonate release and its further cyclooxygenation in a time- and temperature-dependent fashion. The consequent presence of $\mathrm{TxB}_{2}$-the stable breakdown product of $\mathrm{TxA}_{2}$-in serum can be taken as a "marker" of platelet cyclooxygenase activity.

Fig. 1 shows pre-ASA serum $\mathrm{TxB}_{2}$ values in uremic patients and controls. The means were $153 \pm 61$ and $225 \pm 43 \mathrm{ng} / \mathrm{ml}$, respectively. The difference did not reach statistical significance.
ASA reduced serum $\mathrm{TxB}_{2}$ formation in uremics and control subjects. Fig. 5 shows that the effect of ASA was time-dependent and comparable in uremics and controls for both routes of administration. Oral ASA induced maximal inhibition of serum $\mathrm{TxB}_{2}$ within $15 \mathrm{~min}$ in both uremics and controls.

The temporal relation between the detection of ASA in the systemic circulation and acetylation of platelet cyclooxygenase, as reflected by $\mathrm{TxB}_{2}$ generation in serum, is shown in Fig. 5. A significant reduction in serum $\mathrm{TxB}_{2}$ was observed in both uremics and controls before ASA could be detected in the systemic circulation. These findings extend to uremics the previous observation made in normal subjects by Pedersen and FitzGerald (21) that ASA acetylates platelet cyclooxygenase in the presystemic circulation. After intravenous ASA, serum $\mathrm{TxB}_{2}$ was immediately inhibited $(>90 \%)$ in both uremics and control subjects (Fig. 5). In uremics as well as in control subjects, $1 \mathrm{~h}$ after 160 mg of oral ASA serum $\mathrm{TxB}_{2}$ levels was still maximally $(>90 \%)$

Table IV. Pharmacokinetic Findings after Oral and Intravenous Administration of ASA

\begin{tabular}{|c|c|c|c|c|}
\hline \multirow[b]{2}{*}{ Index } & \multicolumn{2}{|l|}{ Uremics } & \multicolumn{2}{|l|}{ Controls } \\
\hline & 160 mg p.o. & $100 \mathrm{mg} / \mathrm{m}^{2}$ i.v. & 160 mg p.o. & $100 \mathrm{mg} / \mathrm{m}^{2}$ i.v. \\
\hline$\lambda_{z}\left(\min ^{-1}\right)$ & $0.034 \pm 0.010$ & $0.052 \pm 0.013$ & $0.037 \pm 0.010$ & $0.040 \pm 0.008$ \\
\hline$t_{1 / 2}(\min )$ & $21.50 \pm 5.20$ & $14.40 \pm 4.40$ & $19.70 \pm 5.70$ & $17.30 \pm 1.40$ \\
\hline $\mathrm{V}\left(\right.$ liter $\left./ \mathrm{m}^{2}\right)$ & $16.80 \pm 6.40$ & $10.80 \pm 2.63$ & $10.17 \pm 4.28$ & $8.81 \pm 1.70$ \\
\hline $\mathrm{CL}\left(\right.$ liter/min per $\left.\mathrm{m}^{2}\right)$ & $0.54 \pm 0.12^{*}$ & $0.54 \pm 0.12^{*}$ & $0.35 \pm 0.05$ & $0.35 \pm 0.05$ \\
\hline AUC $(\mu g \mathrm{~min} / \mathrm{ml})$ & $93.80 \pm 16.60^{\ddagger}$ & $197.60 \pm 46.50^{\ddagger}$ & $152.30 \pm 28.10$ & $289.10 \pm 39.30$ \\
\hline$F(\%)$ & $54.40 \pm 9.30$ & - & $58.10 \pm 8.20$ & - \\
\hline
\end{tabular}

Mean body surface area: uremics, $1.81 \pm 0.12 \mathrm{~m}^{2}$; controls, $1.76 \pm 0.17 \mathrm{~m}^{2}$. Mean unbound fraction of ASA: uremics $0.67 \pm 0.06$; controls $0.36 \pm 0.02$. Abbreviations: AUC, area under concentration-time curve; CL, total body clearance; F, ASA bioavailability; $\lambda_{z}$, elimination rate constant; $t_{1 / 2}$, elimination half-life; $\mathrm{V}$, apparent volume of distribution. ${ }^{*} P<0.02$ uremics vs. controls. ${ }^{\ddagger} P<0.01$ uremics vs. controls. 
Table V. Pharmacokinetic Parameters of SA after ASA Administration

\begin{tabular}{|c|c|c|c|c|}
\hline \multirow[b]{2}{*}{ Index } & \multicolumn{2}{|l|}{ Uremics } & \multicolumn{2}{|l|}{ Controls } \\
\hline & 160 mg p.o. & $100 \mathrm{mg} / \mathrm{m}^{2}$ i.v. & 160 mg p.o. & $100 \mathrm{mg} / \mathrm{m}^{2}$ i.v. \\
\hline$t_{1 / 2}(h)$ & $3.27 \pm 1.76$ & $2.37 \pm 1.27$ & $2.48 \pm 0.35$ & $2.38 \pm 0.60$ \\
\hline AUC $(\mu g h / m l)$ & $39.20 \pm 12.00^{*}$ & $38.20 \pm 17.10$ & $48.60 \pm 11.50^{*}$ & $52.80 \pm 14.10$ \\
\hline $\mathrm{C}_{\max }(\mu \mathrm{g} / \mathrm{ml})$ & $7.86 \pm 2.90^{\ddagger}$ & $10.34 \pm 3.41$ & $14.82 \pm 3.68$ & $14.68 \pm 4.19$. \\
\hline $\mathrm{T}_{\max }(h)$ & $1.44 \pm 0.62$ & $0.86 \pm 0.38$ & $1.04 \pm 0.34$ & $0.55 \pm 0.16$ \\
\hline
\end{tabular}

Abbreviations: AUC, area under concentration-time curve; $C_{\max }$, maximum concentration; $T_{\max }$, time of maximum concentration; $t_{\psi_{2}}$, elimination half-life. ${ }^{*}$ Means \pm SD of AUC normalized by the dose $\left(100 \mathrm{mg} / \mathrm{m}^{2}\right)$. ${ }^{\ddagger} P<0.02$ uremics vs. controls.

inhibited (Figs. 1 and 5). Both oral and intravenous ASA had a long-lasting inhibitory effect on serum $\mathrm{TxB}_{2}$ in uremics and controls. 2 and $16 \mathrm{~h}$ after ASA, serum $\mathrm{TxB}_{2}$ formation was still $>90 \%$ inhibited in both groups $(P<0.01)$ (Fig. 1). The identical time course of inhibition of serum $\mathrm{TxB}_{2}$ after oral and intravenous ASA in uremics and controls indicates an identical sensitivity of uremic and control platelet cyclooxygenase to the inhibitory effect of ASA, thus excluding that the exaggerated prolongation of BT in uremics depends on a particular sensitivity of uremic platelet cyclooxygenase to ASA. Moreover, the dissociation between the transient effect of ASA on BT in uremics and the long-lasting effect on serum $\mathrm{TxB}_{2}$ indicates that ASA affects primary hemostasis in uremia by a mechanism distinct from cyclooxygenase inhibition.

The finding of comparable prolongation of post-ASA BT after the second dose of ASA (Table II), when the effect of the first dose had worn off but Tx was still $>90 \%$ inhibited, further supports the possibility that ASA induces an abnormal prolongation of BT by a mechanism distinct from platelet cyclooxygenase inhibition. This possibility is further supported by the additional finding that ibuprofen administration to uremic patients despite inhibiting $>90 \%$ serum $\mathrm{TxB}_{2}$ was not associated with a prolongation of BT at each interval considered (Fig. 2).

\section{Discussion}

The potential beneficial effect of ASA in preventing thrombosis has been related to its selective, cumulative inhibitory activity

Table VI. Protein Binding of ASA and SA in Plasma of Five Uremic Patients with Anuria and Five Control Subjects*

\begin{tabular}{lllllll}
\hline & \multicolumn{2}{l}{$\begin{array}{l}\text { Uremic } \\
\text { patients }\end{array}$} & ASA & SA & & \multicolumn{2}{l}{$\begin{array}{c}\text { Control } \\
\text { subjects }\end{array}$} & \multicolumn{2}{l}{ ASA } & SA \\
\cline { 2 - 3 } \cline { 6 - 7 } 1 & 33.1 & 92.2 & 1 & 63.0 & 95.5 \\
2 & 31.8 & 91.9 & 2 & 61.1 & 96.2 \\
3 & 42.5 & 92.0 & 3 & 64.8 & 96.2 \\
4 & 29.8 & 88.7 & 4 & 67.1 & 94.5 \\
5 & 28.1 & 91.4 & 5 & 65.8 & 93.2 \\
Average \% & $33.1 \pm 5.6$ & $91.2 \pm 1.5$ & & $64.4 \pm 2.4$ & $95.1 \pm 1.3$
\end{tabular}

Each value is the average of three determinations at high, medium, and low concentration (range $19-0.5 \mu \mathrm{g} / \mathrm{ml}$ ).

* The mean \pm SD of plasma total protein and albumin concentrations were respectively $6.58 \pm 0.35$ and $4.38 \pm 0.21 \mathrm{~g} / \mathrm{dl}$ in uremics and $7.18 \pm 0.39$ and $4.52 \pm 0.27 \mathrm{~g} / \mathrm{dl}$ in controls. on platelet cyclooxygenase $(2,23,24)$. Whether mechanisms other than platelet cyclooxygenase inhibition also play a role in this effect on platelet function remains to be established. In uremia moderate doses of ASA have been used to prevent thrombosis of arterovenous shunts (1). Because moderate doses of ASA abnormally prolong BT in uremics but not in control subjects (7), we became interested in the mechanism by which ASA impairs platelet function in uremia and the relationship between prolongation of BT and platelet cyclooxygenase inhibition.

Although ASA has been reported to determine a moderate prolongation of BT in normals $(25,26)$, the present results confirm our data reported previously (7) and show that ASA does not prolong BT in normal subjects at the doses employed in the present investigation. However, in all the chronic renal failure patients we studied, on regular hemodialysis, selected on the basis of a baseline BT within the normal range or slightly prolonged, post-ASA BT was significantly prolonged.

To verify whether the abnormal post-ASA prolongation of BT in uremics is somewhat related to the degree of renal impairment, we gave oral ASA to normal subjects and patients with different degrees of renal impairment. The finding of highly significant correlation between the serum creatinine values and BT measurements suggests that the prolonged post-ASA BT in renal failure is related to the degree of renal impairment.

A possible explanation for abnormal prolongation of BT by ASA in uremics is that ASA pharmacokinetics and bioavailability are different in uremic patients and in normal subjects. Because ASA pharmacokinetics had not been studied before in renal failure patients, we adapted to uremics a methodology described previously (13) in order to overcome the interference with the analytical assay arising from "toxins" accumulating in uremia. After moderate oral or intravenous doses of ASA, kinetic parameters were evaluated in uremics and in normal subjects. The results showed that $\mathrm{V}$ and $\mathrm{CL}$ were higher in uremics as compared with normal subjects whereas AUC was found to be lower. In contrast, ASA bioavailability was not significantly different between uremics and controls. Our results of an abnormal ASA protein binding in uremia could explain the differences in kinetic parameters. A decreased plasma protein binding may be associated with an increased level of unbound drug with a consequent potentiation in its pharmacologic effect (27). The present results indicate that this was indeed the case in uremics in that the concentration of unbound ASA was higher than in controls given the same ASA dose. We pondered whether these findings may explain the exaggerated effect of ASA on BT in uremia. This issue is difficult to address because in uremia there are multicompartmental equilibria between free ASA and cyclooxygenase and the possibility exists that various uremic toxins compete 

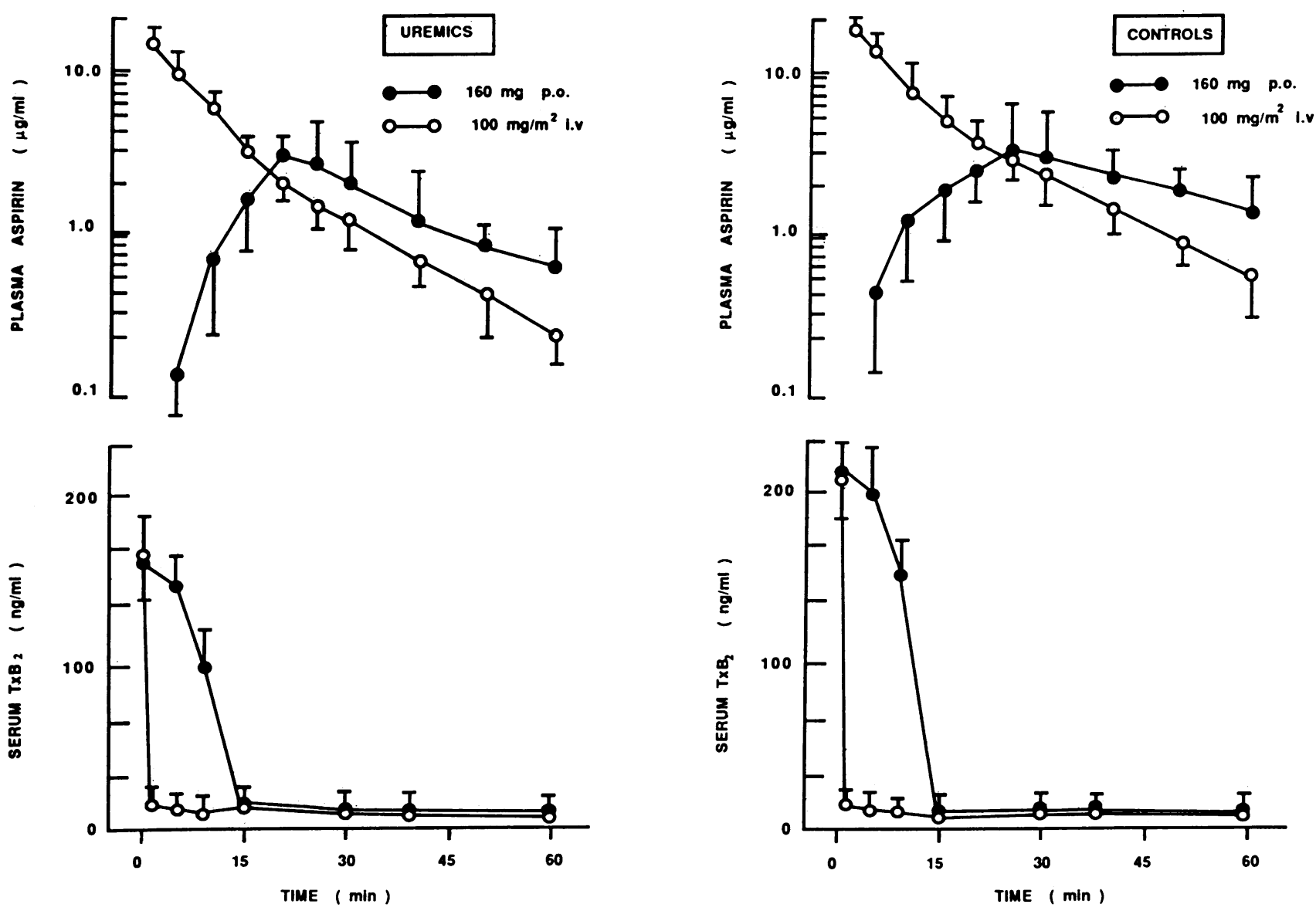

Figure 5. Plasma concentrations of ASA and time course of serum $\mathrm{TxB}_{2}$ after oral and intravenous administration in uremic patients and normal subjects.

with ASA for platelet cyclooxygenase binding. With all these limitations in mind, we have administered to an additional group of normal subjects a higher dose of ASA in order to obtain level of unbound drug comparable to those found in uremics. Failure to obtain a significant prolongation of BT in this latter group of normal subjects indicates that levels of unbound ASA "per se" might not explain the exaggerated post-ASA BT in uremia. However, this approach has the limitation that, for the reasons mentioned above, kinetic interactions in uremic and volunteers may not be comparable even if similar, free ASA concentrations are obtained.

In vivo ASA is rapidly deacetylated to salicylate. Because salicylate-which has not by itself an inhibitory activity on platelet cyclooxygenase-may protect the platelet enzyme from ASA inhibition (28), we wondered whether in uremia the ASA metabolism is impaired to such an extent as to alter the SAASA interaction which has been found (at least in test tube and in certain experimental circumstances in vivo) to counteract the effect of ASA on platelet cyclooxygenase. This possibility is inconsistent with the present findings of similar or even higher concentrations of unbound SA in uremics as compared with controls given the same dose of ASA.

An alternative explanation for the longer post-ASA BT is that in uremia an abnormality in the platelet cyclooxygenase enzyme (11) makes it more susceptible to irreversible acetylation after ASA administration. However, the findings that the time courses of serum $\mathrm{TxB}_{2}$ inhibition by oral and intravenous ASA are identical in uremics and in controls and $1 \mathrm{~h}$ after oral ASA both uremics and controls showed a comparable inhibition of their serum $\mathrm{TxB}_{2}$ generation $(94.0 \pm 4.5 \%$ and $93.3 \pm 4.1 \%$, respectively) make this possibility unlikely. 2 and $16 \mathrm{~h}$ after ASA, serum $\mathrm{TxB}_{2}$ was still $>90 \%$ inhibited in patients as well as in controls suggesting that the irreversible acetylation of platelet cyclooxygenase described in normal subjects also takes place in uremics. One might also consider that the small difference in the percentage of post-ASA serum $\mathrm{TxB}_{2}$ inhibition that we found between uremics and controls may reflect a different degree of inhibition of $\mathrm{TxA}_{2}$-dependent platelet function. However, a comparable inhibition of platelet cyclooxygenase in uremia after 2 and $16 \mathrm{~h}$, whereas BT was prolonged after $2 \mathrm{~h}$ but not after $16 \mathrm{~h}$, tends to exclude that this possibility explains the abnormal post-ASA BT in uremia.

Once a different pharmacokinetics or a peculiar sensitivity of uremic platelet cyclooxygenase to ASA have been excluded, the fact that ASA does not prolong BT in normal subjects whereas it has a marked effect in uremia can be explained by the existence of multiple independent pathways of platelet activation. In normals, the compensatory role taken by pathways other than those inhibited by ASA prevents post-ASA BT from being excessively prolonged. At variance in uremics, ASA might induce an abnormal prolongation of BT because of the simultaneous derangement of different pathways of platelet activation due to the uremic condition. In this context it is of interest that uremic platelets are refractory to platelet-activating factor (PAF)-induced 
aggregation $(29,30)$. The platelet response to PAF in vitro has been tested in the patients under consideration here, and found to be markedly impaired or absent (data not shown). Within the limits that the role of PAF in primary hemostasis has not been defined yet, one can speculate that in uremics the sudden inhibition of $\mathrm{TxA}_{2}$ synthesis adds to the defective platelet response to PAF resulting in an increase in post-ASA BT. One of the problems with this interpretation is that serum $\mathrm{TxB}_{2}$ is equally inhibited 1 and $16 \mathrm{~h}$ after ASA in uremics whereas BT is prolonged at $1 \mathrm{~h}$ but has returned to basal values at $16 \mathrm{~h}$.

Actually the temporal dissociation between the effect of ASA on platelet $\mathrm{TxA}_{2}$ synthesis and the effect on $\mathrm{BT}$ in uremia suggests that ASA may have two distinct inhibitory effects on platelet function: a long-lasting effect which blocks platelet $\mathrm{TxA}_{2}$ generation and a transient effect which interferes with one of the determinants of normal BT. It is noteworthy that, at variance with the effect on serum $\mathrm{TxB}_{2}$, the effect of ASA on BT is dependent on the presence of ASA in circulating blood. When plasma ASA concentration decreased the effect on BT was less pronounced, and no more prolongation of BT was seen when ASA was no longer detectable in plasma.

Altogether, these observations suggest that studies on BT in uremia may have unmasked a new mechanism by which ASA inhibits platelet function which, on theoretical grounds, might also operate in the nonuremic population. As an alternative explanation of the abnormal prolongation of post-ASA BT in uremia, the possibility of BT being influenced by vascular rather than platelet variables can also be taken into account. If one assumes that vascular Tx formation is increased in uremia, our results can be interpreted in light of the ASA-induced transient inhibition of vascular $\mathrm{Tx}$, thus reducing the vasoconstrictory effect and the Tx-mediated platelet vessel wall interaction that can be important determinant of a given BT. Because vessels can resynthesize cyclooxygenase faster than platelets, BT may normalize as a consequence of a newly synthesized cyclooxygenase allowing a normal vascular $\mathrm{T} x$ formation.

In conclusion, the present studies suggest that, unlike in normal subjects, in uremic patients ASA consistently induces a marked prolongation of BT. This prolongation is transient and cannot be demonstrated longer when plasma ASA concentrations are undetectable. The different post-ASA BT in uremics and controls does not appear to be a consequence of peculiar ASA pharmacokinetics inasmuch as the differences we have found in ASA and SA kinetic parameters, in uremia in comparison with normal subjects, are not such to justify an exaggerated effect of ASA on platelet function inhibition. In both uremics and controls, moderate doses of ASA induced longlasting inhibition of platelet $\mathrm{TxA}_{2}$ synthesis, indicating irreversible acetylation of the platelet enzyme in both conditions. The temporal dissociation between the effects of ASA on BT and on platelet $\mathrm{TxA}_{2}$ generation suggests that mechanisms other than cyclooxygenase inhibition are responsible for the inhibitory effect of ASA on platelet function in uremia. The finding of a prolonged BT, after the second dose of ASA given when the effect of the first one on BT was worn off but serum $T x$ was still inhibited, actually indicates that ASA-induced prolongation of BT in uremics may be independent of cyclooxygenase inhibition. Finally, our present results that ibuprofen at a dose that fully suppresses platelet cyclooxygenase is unable to prolong BT in uremics further support the concept that ASA-induced prolongation of BT in uremia is independent of platelet cyclooxygenase inhibition.

\section{Acknowledgments}

We thank Drs. Giuliano Mecca and Giulio Mingardi for allowing us to study their patients, Dr. Ariela Benigni for radioimmunoassay measurements, and Massimo Locatelli for technical assistance. We are indebted to Professor Carlo Patrono and Dr. Giovanni de Gaetano for critically reviewing this manuscript. Judy Baggott and Cristina Signorelli helped prepare the manuscript.

This work was supported by a grant from the National Research Council (Italy) program "Tecniche Sostitutive di Funzioni d'Organo," contract no. 85.00328 .04 , and partially by funds from the National Institutes of Health (U. S.), contract no. 1 R01 HL-37491-01. Dr. Orisio is the recipient of a fellowship of the Opera Pia Misericordia Maggiore.

\section{References}

1. Harter, H. R., J. W. Burch, P. W. Majerus, N. Stanford, J. A. Delmez, C. B. Anderson, and C. A. Weerts. 1979. Prevention of thrombosis in patients on hemodialysis by low-dose aspirin. N. Engl. J. Med. 301:577-579.

2. Majerus, P. W. 1983. Arachidonate metabolism in vascular disorders. J. Clin. Invest. 72:1521-1525.

3. Eknoyan, G., and C. H. Brown. 1981. Biochemical abnormalities of platelets in renal failure: evidence for decreased platelet serotonin, adenosine diphosphate and $\mathrm{Mg}$-dependent adenosine triphosphatase. Am. J. Nephrol. 1:17-23.

4. Salzman, E. W., and L. L. Neri. 1966. Adhesiveness of blood platelets in uremia. Thromb. Diath. Haemorrh. 15:84-92.

5. Livio, M., A. Benigni, and G. Remuzzi. 1985. Coagulation abnormalities in uremia. Semin. Nephrol. 5:82-90.

6. Deykin, D. 1983. Úremic bleeding. Kidney Int. 24:698-705.

7. Livio, M., A. Benigni, G. Viganò, G. Mecca, and G. Remuzzi. 1986. Moderate doses of aspirin and risk of bleeding in renal failure. Lancet. i:414-416.

8. Cutler, R: E., K. H. Krichman, and A. D. Blair. 1983. Drugs in renal failure. Pharmacokinetics of drugs and the effects of renal failure. In Textbook of Nephrology. Williams \& Wilkins Co., Baltimore. 8.428.62 .

9. Roth, G. J., N. S. Standford, and P. W. Majerus. 1975. Acetylation of prostaglandin synthase by aspirin. Proc. Natl. Acad. Sci. USA. 72: 3073-3076.

10. Roth, G. J., and P. W. Majerus. 1975. The mechanism of the effect of aspirin on human platelets. J. Clin. Invest. 56:624-632.

11. Remuzzi, G., A. Benigni, P. Dodesini, A. Schieppati, M. Livio, G. de Gaetano, J. S. Day, W. L. Smith, E. Pinca, P. Patrignani, and C. Patrono. 1983. Reduced platelet thromboxane formation in uremia: evidence for a functional cyclooxygenase defect. J. Clin. Invest. 71:762768.

12. Mays, D. C., D. E. Sharp, C. A. Beach, R. A. Kershaw, J. R. Bianchine, and N. Gerber. 1984. Improved method for the determination of aspirin and its metabolites in biological fluids by high-performance liquid chromatography: applications to human and animal studies. $J$. Chromatogr. 311:301-309.

13. Gaspari, F., and M. Locatelli. Determination of aspirin and salicylic acid in uremic patients' plasma using reversed-phase high-performance liquid chromatography. Ther. Drug Monit. In press.

14. Gibaldi, M., and B. Perrier. 1975. Pharmacokinetics. Marcel Dekker, Inc. New York.

15. Friedman, M. 1937. The use of ranks to avoid the assumption of normality implicit in the analysis of variance. J. Am. Stat. Assoc. 32: 675-701.

16. Linton, M., and P. S. Gallo. 1975. The Practical Statistician: Simplified Handbook of Statistics. Brooks/Cole Publishing Company, Monterey.

17. Steiner, R. W., C. Coggins, and A. C. A. Carvalho. 1979. Bleeding time in uremia: a useful test to assess clinical bleeding. Am. J. Hematol. 7:107-117.

18. Mannucci, P. M., G. Remuzzi, F. Pusineri, R. Lombardi, C. 
Valsecchi, G. Mecca, and T. S. Zimmerman. 1983. Deamino-8-D-arginine vasopressin shortens the bleeding time in uremia. N. Engl. J. Med. 308: 8-12.

19. Andreasen, F. 1973. Protein binding of drugs in plasma from patients with acute renal failure. Acta Pharmacol. Toxicol. 32:417-429.

20. Hawkins, D. R., N. Pinckard, I. P. Crawford, and R. S. Farr. 1969. Structural changes in human serum albumin induced by ingestion of acetylsalicylic acid. J. Clin. Invest. 48:536-542.

21. Pedersen, A. K., and G. A. FitzGerald. 1984. Dose-related kinetics of aspirin: presystemic acetylation of platelet cyclooxygenase. $N$. Engl. J. Med. 311:1206-1211.

22. Rowland, M., S. Riegelman, P. A. Harris, and S. D. Sholkoff. 1972. Absorption kinetics of aspirin in man following oral administration of an aqueous solution. J. Pharm. Sci. 61:379-385.

23. Patrignani, P., P. Filabozzi, and C. Patrono. 1982. Selective cumulative inhibition of platelet thromboxane production by low-dose aspirin in healthy subjects. J. Clin. Invest. 69:1366-1372.
24. Marcus, A. J. 1983. Editorial retrospective. Aspirin as an antithrombotic medication. N. Engl. J. Med. 309:1515-1516.

25. O'Grady, J., and S. Moncada. 1978. Aspirin: a paradoxical effect on bleeding-time (Letter). Lancet. ii:780.

26. Deykin, D., P. Janson, and L. McMahon. 1982. Ethanol potentiation of aspirin-induced prolongation of the bleeding time. $N$. Engl. J. Med. 306:852-854.

27. Odar-Cederlof I., and O. Borga. 1974. Kinetics of diphenylhydantoin in uraemic patients: consequences of decreased plasma protein binding. Eur. J. Clin. Pharmacol. 7:31-37.

28. de Gaetano, G., C. Cerletti, E. Dejana, and R. Latini. 1985. Pharmacology of platelet inhibition in humans: implications of the salicylate-aspirin interaction. Circulation. 72:1185-1193.

29. Rao, A. K. 1986. Uraemic platelets. Lancet. i:913-914.

30. Livio, M., P. M. Mannucci, G. Viganò, G. Mingardi, R. Lombardi, G. Mecca, and G. Remuzzi. 1986. Conjugated estrogens for the management of bleeding associated with renal failure. N. Engl. J. Med. 315: 731-735. 